\title{
Constructions of Climate Change on the Radio and in Nepalese Lay Focus Groups
}

To date analyses of media climate change constructions have mostly focused on coverage in western newspapers. Consideration of coverage in developing countries, and analyses of media constructions alongside local understandings of climate change are comparatively rare. This article provides an analysis of the construction of climate change on Nepalese radio and lay constructions of environment and climate change within the country. Data from a radio programme and six focus groups are analysed. Analysis of the radio programme indicated that climate change was portrayed as a certain reality with national impacts caused by the actions of the West. While climate change dominated the radio headlines, in focus groups local environmental problems received far more attention. The paper aims to both inform directions for future climate change communication in Nepal and the wider research agenda.

Keywords: Climate change; Radio; Local constructions; Developing country; Nepal

\section{Introduction}

While analyses of media coverage of climate change and public reception of media accounts proliferate, to date these have focused almost exclusively on the situation in developed ${ }^{\mathrm{i}}$ countries. The wealth of research on coverage of climate change in developed countries stands in stark contrast to the dearth of research in developing countries. As Doulton and Brown (2009: p.191) point out, the vulnerability of poor countries to the impacts of climate change is "widely acknowledged", however:

\footnotetext{
${ }^{1}$ Sangita Shrestha is a Ph.D. candidate in the Department of Sociology, University of Surrey, UK. Kate Burningham is Senior Lecturer in Sociology, University of Surrey, UK, and Colin B. Grant is Pro-ViceChancellor (International Relations) at the University of Surrey, UK. Correspondence to: Sangita Shrestha, 3 Little Paddock Close, Crawley, West Sussex RH11 0BN, UK. Email: sangita@environcomms.com

Current Affiliations: Sangita Shrestha is a Visiting Researcher at the Department of Sociology, University of Surrey and also a Research Associate at Centre for Nepal Studies UK (CNSUK). Colin B. Grant is Pro-Vice-Chancellor, Internationalisation, University of Bath, UK.
} 
"To date, almost all research on the communication of climate change has focused on Western social contexts and norms, with little consideration of how the issue is being framed in other countries where the macro-scale normalising values in the public sphere are different” (Billet, 2009, p.2).

Research in developing countries is particularly important as they are often most vulnerable to climate impacts and least responsible for greenhouse gas emissions (Oxfam International, 2008). The field of media research on climate change now needs to provide more empirical explorations of how the issue is being constructed in the media and by publics in developing countries. This paper responds to this by providing a case study of radio and local constructions of climate change in Nepal, a country identified as the 4th most vulnerable in the world to the impacts of climate change (Climate Change Vulnerability Index, 2011).

Since the early 1990s research on media coverage of climate change within developed countries has burgeoned. The literature includes studies in the United States (Antilla, 2005; Dispensa \& Brulle, 2003; Nisbet \& Mooney, 2007), United Kingdom (Carvalho, 2007; Doulton \& Brown, 2009; Ereaut and Segnit, 2006), New Zealand (Bell, 1991; Kenix, 2008), Germany (Peters \& Heinrichs, 2008; Weingart, Engels, \& Pansegrau, 2000), The Netherlands (Dirikx \& Gelders, 2010), Sweden (Hoijer, 2010) and Japan (Sampei \& Aoyagi-Usui, 2009). Studies vary in their focus drawing attention to media framings (Antilla, 2005; Ereaut \& Segnit, 2006; Dirikx \& Gelders, 2010; Doulton \& Brown, 2009; Nisbet \& Mooney, 2007; Peters \& Heinrichs, 2008), changing perceptions on climate change (Weingart et al., 2000), emotion attached to climate change discourses (Hoijer, 2010), ideological influences (Carvalho, 2007), media reporting and public understanding of climate change (Bell, 1991) 
and correlation between climate change coverage and public concern (Sampei \& AoyagiUsui, 2009).

Despite such variation, one recurrent observation is that climate change is often framed in terms of debate, controversy or uncertainty (see Antilla, 2005; Dispensa \& Brulle, 2003; Doulton \& Brown, 2009, Ereaut \& Segnit, 2006; Nisbet \& Mooney, 2007). Analysis shows that the US has more scepticism in its coverage than other developed countries such as New Zealand or Finland (Dispensa \& Brulle, 2003). Similarly, climate change discourse in the UK press is also found to be 'confusing', 'contradictory', 'chaotic’ (Ereaut \& Segnit, 2006: p.7), and uncertain (Doulton \& Brown, 2009). Studies in the United Kingdom (Ereaut \& Segnit, 2006; Hulme, 2007) and Germany (Peters \& Heinrichs, 2008) further suggest that alarmism dominates climate change discourses, with the issue often depicted as "awesome, terrible, immense” and beyond the control of human beings (Ereaut \& Segnit, 2006, p.7). Such contradictory, uncertain and alarmist media discourses are thought to lead to public confusion and helplessness (Antilla, 2005; Dispensa \& Brulle, 2003; Ereaut \& Segnit, 2006).

A few recent studies provide early indications of key ways in which coverage within developed and developing countries may correspond and differ. Billet's (2009) study of climate change in the Indian press indicates that in contrast to much western coverage there is a lack of scepticism about the reality of climate change; rather the issue is framed in terms of risks and impacts within the country while responsibility is laid firmly at the feet of developed nations. Takahashi's (2011) analysis of newspaper coverage of climate change in Peru focuses on sources rather than framings. However, he also draws attention to the acceptance of climate change and indicates a focus on national vulnerability to impacts and international political framing. In terms of sources, in common with findings in developed 
countries (e.g. Kenix, 2008; Dispensa \& Brulle, 2003), he points to a dominance of elite discourses on climate change with little attention to effects on more vulnerable populations within the country. Similarly, Billet's analysis also points to the way in which Indian newspapers reflect concerns of industrial elites and downplay their responsibility for India's increasing emissions. Both Billet and Takahashi’s analyses are based on newspaper coverage which Billet acknowledges is a source of information only for the literate public, and neither provide insight into audience evaluations of media coverage.

Interest in how climate change is framed in the media is usually at least partly motivated by an understanding that the media play a key role in the construction of environmental meaning (Hansen, 2010). Much of the literature, however, speculates about the effects of particular constructions of climate change on public understanding but restricts analysis to media texts (mainly newspapers). As Olausson (2011, p. 282) notes, claims about the media's role in shaping citizen's understandings of environmental risk "are rarely verified with reference to empirical studies on the relationship between media output and audience reception”. Alongside scrutiny of media content is a need for investigation of the local constructions of actors in particular cultural, economic and social contexts (Anderson, 1997). While there is a corresponding research interest in public constructions and understandings of climate change (e.g. Whitmarsh, 2005; Sharples, 2010; Olausson, 2011; Wibeck, 2012; Colom \& Pradhan, 2013), there are few studies which combine analyses of media and public constructions, Bell's (1991) study in New Zealand, Corbett and Durfee's (2004) in the US, and Sampei and Aoyagi-Usui's (2009) in Japan are useful exceptions. The relative paucity of studies which explore both aspects is understandable as it is difficult to do justice to both media and public constructions within one paper; it is, however, an area which deserves more attention. 
Thus little is known about media constructions of climate change in developing countries; most existing studies of climate change communication in the media are based on analysis of newspapers. Moreover, there is little research which attempts to complement understanding of media coverage of climate change with insights into public constructions. This paper responds to all of these research gaps by focusing on the construction of climate change on the radio and amongst publics in Nepal.

Nepal, with a population of 26.5 million, has recently made progress in poverty reduction but remains one of the poorest countries in the world with $30 \%$ of the population living below the poverty line. The majority of the population (80\%) lives in rural areas and their livelihoods are based on subsistence farming. While the country has played almost no role in the creation of global warming (Himalayan Climate Initiatives, 2013), research suggests that the “[e]vidences of climate change impact are already visible in vegetation, hydrology, and rising temperature affecting normal plant productivity and ecosystem services in Nepal” (Khatiwoda, 2011: p. IV). Within the country, Nepal is typically framed as one of the locations most vulnerable to climate change impacts with the developed nations being considered responsible for causing the problem (Shrestha, 2012; ICIMOD, 2010).

In this paper we explore how climate change is framed in Nepal both on the radio and in local accounts through two distinct but related strands of analysis: first via examination of discourses in a radio programme and second through data generated in focus group discussions. The research was guided by the following questions:

- Which issues are prioritised in Batabaran Dabali ${ }^{i i}$ and what news sources relied upon?

- How does Batabaran Dabali radio programme represent climate change? 
- How is climate change constructed among rural and urban lay publics?

- What role do media communications, particularly those of Batabaran Dabali, play in local constructions of environment and climate change?

\section{Methods}

The study included a combination of quantitative and qualitative research methods including quantitative content analysis of radio programmes dealing with environmental issues, focus group discussions, and a short questionnaire survey administered to participants.

Radio is the only medium which reaches most households in Nepal; television follows the radio in terms of accessibility, with print publications in third place. Nepal's literacy rate (population aged 5 years and above) has increased from 54.1\% in 2001 to $65.9 \%$ in 2011 (Central Bureau of Statistics Nepal, 2012). However, more than 30\% of the population are unable to read print media. Although television technically reaches $72 \%$ of the population (Nepal Television, 2012) poverty restricts many households from owning a television set. A Broadcast Audience Survey in 2006 (Equal Access, 2006-2007) found that radio and television were equally the most (80\%) preferred sources of media in Nepal. More recently in 2013 Colom and Pradhan's research demonstrated that radio plays a bigger part than TV as an information source with most people having access to a radio and it being the preferred medium for rural respondents and farmers. Since radio is still the principal medium for communicating climate change in Nepal, particularly in rural areas (Colom and Pradhan, 2013), we decided to focus on radio in order to gain an understanding of climate change communication which has relevance for a significant audience in Nepalese society. Moreover, there was no regular environment programme on television stations in Nepal during the study period. 
The recorded programmes of Batabaran Dabali, aired on Radio Sagarmatha from May 2009 to April 2010, were collected for this study. Radio Sagarmatha is available to residents of the whole of Kathmandu valley and many neighbouring districts. Programmes are also relayed and re-broadcast by various local community radio stations in Nepal. In this way, Radio Sagarmatha is available to up to 10 million listeners (Radio Sagarmatha brochure, n.d.). The station is credited with changing the media landscape in Nepal by giving voice to people unheard by other radio stations (Pringle, 2008) and has received national awards for advocating issues related to development, environment, public health and sanitation (Radio Sagarmatha brochure, n.d.). Although Batabaran Dabali is the longest running environment programme in Radio Sagarmatha, to date no audience profile for the programme has been produced.

Quantitative content analysis was conducted on the data from Batabaran Dabali to provide an initial systematic analysis of textual content as a basis for subsequent qualitative analysis (Hansen, Cottle, Negrine \& Newbold, 1998; Spicer, 2004). Quantifying the presence and frequency of content, the data was categorised in terms of the mention of environmental issues including climate change ${ }^{\mathrm{iii}}$, and sources drawn upon. A code book was developed alongside the coding schedule to ensure clarity and consistency in the categorisations. The coding schedule was tested initially with a sample of the data and all the authors were involved in refining the classifications and categories. The content analysis enabled us to answer our first research question; identifying which issues were prioritised in the radio coverage and which sources were relied upon. In order to explore in depth how Batabaran Dabali represented climate change and how lay publics constructed the issue we turned to qualitative analysis. Our qualitative approach was informed by a social constructionist perspective (Anderson, 1997; Burningham, 1998; Hannigan, 2006; Hansen, 1991, 2010; 
Lester, 2010; Yearley, 1991) which focuses on how environmental problems are characterised with specific attention paid to details of discourses and constructions used by participants (Burningham, 1998; Potter \& Wetherell, 1987; Tonkiss, 2004; Seale, 2004; Mason, 2002). We paid attention to the use of key words, phrases and representations to identify, for example, the use of alarmist repertoires, discourses of victimhood and elite discourses.

Alongside collection of the media data, focus groups were held to explore local constructions of environmental issues and to explore the role that media communications, particularly those of Batabaran Dabali, played in these. Focus groups were chosen as the interpretation of media content by audiences is an inherently social activity (Tonkiss, 2004) and they provide opportunities for “eliciting, stimulating, and elaborating audience interpretations” (Hansen et al., 1998, p. 262). We used contacts in Nepal (friends and representatives of governmental and environmental organisations) to recruit participants (both directly and through their contacts). A total of 63 “economically active” Nepalese people (25 male and 38 female - 32\% 20-30 years; 33\% 31-40 years; 30\% 41-50 years and 5\% 51-60 years) participated in 6 focus groups $^{\mathrm{iv}}$. Three groups were with city professionals from Kathmandu valley and three were rural groups (one with farmers in the Sindhupalchowk district and two with community forest users of the Kavrepalanchowk district). Choice of locations was informed by considering the reception profile of Radio Sagarmatha and the need to recruit participants from both rural and urban areas. Since the station's direct transmission capacity is limited to Kathmandu and the nearby areas of the valley, these areas were selected for the study.

The focus group discussions in Nepal lasted around 2 hours using an interview guide which included questions ${ }^{\mathrm{V}}$ on local and global environment and the media and their role in communicating environmental issues. As participants had diverse educational backgrounds ${ }^{\mathrm{vi}}$ 
the questionnaire was developed in both English and Nepali. The purpose of the study was clearly explained and participants were ensured anonymity ${ }^{\mathrm{vii}}$. At the start of each focus group questionnaires were administered which collected information about which media participants used most, whether they remembered any recent media coverage on the environment and whether they ever listened to Radio Sagarmatha and Batabaran Dabali in particular.

Focus group discussions were recorded in full and audio recordings of a year's Batabaran Dabali programmes were received on CD from Radio Sagarmatha. The data from focus groups and radio programmes were transcribed verbatim in Nepali using "Transcription Buddy" software and entered into NVivo8 to facilitate systematic coding and data retrieval. Translation into English only occurred after analysis for any quotes selected for inclusion in the findings. The emphasis was on 'free' translation to achieve contextual equivalence of the data (Birbili, 2000).

Analysis of the focus group data employed established techniques of thematic coding (Coffey \& Atkinson, 1996). An iterative process of deductive and inductive coding categorised the data into: 'Defining the Environment', 'Environmental Organisations', 'Environmental Impacts', 'Environmental Problems’, 'Climate Change’, 'Government', 'Generating Hope’, 'Environmental Future', 'Self Reflexivity', 'Environmental Reporting', 'The Interim Constitution', 'Radio Sagarmatha', 'Batabaran Dabali' and 'Environment, Citizen and Civic Responsibility’. As with the radio data our analysis then focused on how these issues were discussed. 
Our presentation of findings begins by considering how climate change was framed in Batabaran Dabali, drawing attention to the prominence given to the issue, reliance on expert sources and framing of international injustice. We then move on to consider local constructions and show that in contrast to media accounts, climate change received comparatively little attention with issues having direct local impact being prioritised.

\section{Climate Change: The Dominant Environmental Discourse in Batabaran Dabali}

The content analysis of Batabaran Dabali identified climate change as the most newsworthy topic accounting for $28.6 \%$ of the total headline ${ }^{\text {viii }}$ coverage. The second highest coverage was for biodiversity conservation (14.3\%) such as fauna and flora conservation, wetland conservation and community forestry. It was followed by $12.5 \%$ of the headlines coverage on the interim constitution and $5.4 \%$ on citizens' environmental rights. A total of $8.9 \%$ of the programmes also had a focus on the importance of landscape conservation such as that of Churia $^{\mathrm{ix}}$ and Lumbini $^{\mathrm{x}}$ conservation. The remaining coverage focused on diverse environmental issues within Nepal ranging from the impact of environmental pollution on traffic police, to environmental impacts on the Himalayas and general coverage of various nature and natural resource issues. Out of the 50 programmes, 36 included at least once reference to climate change. The keyword count found climate change to be the most frequently cited (244 times) environmental issue. The analysis clearly indicates that while Batabaran Dabali addresses various environmental issues, climate change coverage dominates. 


\section{Primary Definers of Climate Change and the Voice of the 'Voiceless'}

Among 69 interviewees on the programmes, 24\% were high-level government officials, 19\% were affiliated to national and international non-government organisations (NGOs) based in Nepal and 13\% were members of the Constituent Assembly. In addition, 12\% were from universities in Nepal and abroad, and 10\% were from the media, mainly environmental journalists. Although $16 \%$ of the interviewees' organisational affiliations were not specifically mentioned, conversations during the interviews revealed connections with the government or NGOs. The remaining $6 \%$ of interviewees were from various sectors such as the hotel association. It is clear from the analysis that elites tend to have the most newsworthy voices. Government authorities, NGO officials, members of political parties, academics, and media professionals define the problems associated with climate change in Nepal.

While Radio Sagarmatha promotes itself as "the voice of the voiceless" we found that the voices of local communities were under-represented. Content analysis revealed that out of the 50 programmes, only 5 included local voices and opinions. The interviews ranged from just six seconds to a maximum of five minutes. The time allocated (38 minutes and 18 seconds) to twenty six ordinary people amounted to just $3 \%$ of the total time allocated for the 50 programmes aired (20 hrs 37 minutes). The analysis demonstrated clearly that ordinary people were largely excluded from participation and experts dominated radio representations of the environmental agenda in Nepal. Moreover, it revealed how Batabaran Dabali largely served as a forum for elite environmental discourses primarily for exchanging environmental knowledge among elites themselves rather than communicating with ordinary Nepalese people. 


\section{The Representation of Climate Change in Batabaran Dabali}

In line with Billet's (2009) analysis of Indian media coverage, the majority of interviewees and the host in Batabaran Dabali framed climate change as already having observable national impacts. For example, in the following excerpts, the interviewees not only emphasised how all environmental problems were linked to climate change, but also stressed how people had started to witness the impacts:

\footnotetext{
"Everything is being affected by climate change ... that is the effects in agriculture, water resources, and everything.” (Sushila Pundit, Campaigner, Nepalese Youth for Climate Action, Batabaran Dabali, 1 November 2009)

"You see, this is well known to everyone that the climate is changing. We have been seeing it in our everyday life daily. It has a tremendous impact in Nepal. Its effect is being witnessed worldwide.” (Mr. Adarsha Pokharel, Climate Change Expert, Batabaran Dabali, 10 May 2009)
}

Doulton and Brown term this kind of media discourse as “disaster strikes”, which focuses on the "terrible consequences that dangerous climate change is already having on the developing world” (2009, p195). The impact of climate change is emphasised thorough the use of extreme case formulations (Pomerantz, 1986) with 'everything' being said to be affected and 'everyone' aware of this. The focus on national impacts was reinforced by reference to international assessments that recognise the vulnerability of Nepal:

"We are highly at risk. We are among the 7 countries which are highly at risk." (Sushila Pundit, Campaigner, Nepalese Youth for Climate Action, Batabaran Dabali, 1 November 2009) 
Here though the focus was on future risks rather than current impacts. While the language of risk permeated the narratives, discussion of how climate change would affect Nepal in the future was often framed more in terms of certainty than future risk:

"Climate change impact will be faced by everyone irrespective of which political philosophy you believe in or whether you are involved in politics or not, or whether you are a leader or an ordinary citizen, man or a woman, it is inevitable.” (Sunil Babu Pant, Constitution Assembly Member, Batabaran Dabali, 25 October 2009)

We note here that climate change is framed as something that 'will' affect everyone, it is 'inevitable'. In addition, this universal construction of impact downplays the significance of social divisions based on political ideology, class, or gender within the context of climate change (Billet, 2009). Despite such acknowledgements of the reality and future universal threat of climate change (see Billet, 2009; Takahashi, 2011) some interviewees asserted that more or better data were still needed. However, this was not evidence of scepticism about the reality of the problem, so much as appeals for more climate research within the country:

"No study or research has been carried out on these (climate change) issues. We are only talking on the basis of old historical data.” (Subodh Gautam, Environmental Journalist, Batabaran Dabali, 18 October 2009)

"Therefore, there is no data on how the climate is changing and how it has affected the different geographical locations in Nepal. So, whatever we say, it is just guesswork.” (Dr Toran Sharma, Environmentalist, Batabaran Dabali, 16 August 2009) 
Climate change impacts and risks were portrayed as alarming and unstoppable:

"We cannot stop the rise in world temperature...We cannot reduce the worldwide effect of climate change.” (Prakash Sharma, Interviewer, Batabaran Dabali, 16 August 2009).

According to Ereaut and Segnit, although such alarmist repertoires try "to bring climate change close to people's lives” (2006, p.13), the effect is often to distance people from the problem. In a few cases, however, interviewees, including the host considered that climate change could be countered. For example: "We can definitely reduce it and adjust to it (climate change)” (Prakash Sharma, Interviewer, Batabaran Dabali, 16/08/09). A similar construction was evident in the following example in which the interviewee framed climate change as a solvable problem:

"Definitely the impact of climate change will be less if we practise the practical knowledge and expert formulas of our ancestors.” (Rabindra Nath Bhattarai, Assistant Professor, Batabaran Dabali, 07 March 2010).

In the excerpt above, the interviewee portrayed the people of earlier generations as environmentally sensitive and suggested that traditional cultural practices (such as planting of trees) could contribute to mitigating climate change. This notion of cultural significance in environmental conservation was repeated several times across various interviews. While concern about climate change focused on impacts within Nepal, responsibility was seen to lie with developed countries (see Billett, 2009).

"Westerners are generating unstoppable carbon...The big developed countries are [the ones] responsible for excessive carbon emissions [...]” (Modnath Prashrit, Politician and Writer, Batabaran Dabali, 03 May 2009) 
"It is just like us getting punishment for a crime we have not committed." (Adarsha Pokharel, Climate Change Expert, Batabaran Dabali, 10 May 2009)

Such victimisation was attributed to Nepal being a poor nation:

"Firstly, we do not have skills...neither do we have technology nor knowledge. We lack resources too. That is the reason we are going to be the victims.” (Dr. Ravi Sharma Aryal, Joint Secretary, Water and Energy Commission Secretariat, Batabaran Dabali, 13 December 2009)

The narrative frames Nepal as helpless and unable to avoid the punishing impacts of climate change since the country is lagging behind in every aspect of social life.

Both the host and expert interviewees denied Nepal's contribution to climate change, using a discourse of victimhood with the use of metaphors such as 'punishment', 'suffering', 'victim', 'trapped' etc. Such negative descriptors label others implicitly or explicitly as "responsible agents, who are consciously, intentionally and cynically aware of what they do and of the consequences of their actions" (van Dijk, 1998 p.58). Here, an “in-group” designator 'we' is used to distinguish between the developing and the developed nations. Van Dijk (1998, p.58) terms these types of designators "polarization” in which using the "logic of Ingroup-Outgroup relations, the Others are presented as a threat”. Thus the experts' understanding of climate change in Batabaran Dabali was found to use ideological metaphors, identifying Nepal as a helpless country treated unjustly by developed countries.

Some interviewees along with the programme host suggested that the country was further adversely affected as their development activities were constrained by climate change mitigation policies (such as emission caps): 
“They (the developed nations) should also give developing nations a chance to grow, shouldn't they? Sometimes they say that they will co-operate with us in terms of our development. Why do they make us live in such a hope? Why are they making us more dependent on them?” (Prakash Sharma, Interviewer, Batabaran Dabali, 13 December 2009)

“They (developed countries) have reached the pinnacle of their development....and now they don't let us do that...It is very difficult for us (developing nations) as development is not possible without greenhouse gas emissions.” (Adarsha Pokharel, Climate Change Expert, Batabaran Dabali, 10 May 2009)

In summary, the analysis clearly suggests that in Batabaran Dabali climate change was emphasised over other environmental problems. Climate change was presented as a certainty (whether now or in the future) with dire impacts for Nepal. The blame was laid squarely at the feet of the developed countries. Despite this clear consensus, there were variations in the discourse with climate change being variously portrayed as: "seen already", "it will happen in future”, "just guesswork" and as something which "we can reduce” or something "we cannot stop”. According to Ereaut and Segnit (2006, p.7), this kind of “confusing, contradictory and chaotic" climate change discourse gives the impression of a "discourse in tension" which generates the meta-message "nobody knows!" potentially making publics even more confused.

\section{Framing Climate Change in Local Contexts}

In the questionnaire distributed during the focus groups, we asked participants "which media do you use the most?”xi Somewhat to our surprise the majority (31) recorded TV as their 
most used media outlet. Only 14 claimed that they used newspapers the most and only 9 recorded that they used radio the most and 9 that they used the Internet as their primary source. If we combine the data for first and second most used however, the gap between TV and radio narrows - TV received $42 \%$ of first and second preferences; radio $27 \%$, newspapers 21\% and Internet 9\%. While our data are limited, they do indicate the continuing importance of radio communication in rural areas - $63 \%$ of first and second preferences for TV were provided by rural participants but $91 \%$ of first or second preferences for radio came from rural participants. Participants from the city were more likely to record first or second preference for newspapers - $84 \%$ of first or second preferences for papers came from city dwellers.

We found that $33.3 \%$ of participants said they sometimes listened to Radio Sagarmatha but only $2 \%$ claimed to be regular listeners of Batabaran Dabali. The majority of listeners to the station were from the urban professional groups, less than one third of rural people listened to it. Thus we are not able strictly to conceive of our focus groups as audience research; the majority of our participants were not an audience for Batabaran Dabali. However, in line with other studies (e.g. Olausson, 2011) it still makes sense to use the focus groups to explore respondents' views on media reporting of climate change and the role that media communications, particularly those of Batabaran Dabali, play in local constructions. In addition as Radio Sagarmatha explicitly aims to be the voice of the voiceless, to promote citizen rights and to be an accessible community radio our finding that the target audience simply were not listening to the station was significant. The focus group discussions explored participants' constructions of environmental issues and the role media communications, particularly those of Batabaran Dabali, played in these. We did not ask specifically about 
climate change initially, allowing participants to raise and discuss the issues which they prioritised.

The majority of participants claimed that environmental stories were not appealing to them compared to the coverage of other topics in the media, indicating that environment programmes, especially those aired by the radio, may not compel audience attention:

“We don’t pay much attention to environmental stories. Actually, these are not attractive.” (Samjhana/BP ${ }^{\mathrm{xii}}$ )

"I have not much interest in environmental media coverage now.” (Kavita/ITP)

Thus not only was the explicitly environmental radio station, Radio Sagarmatha, scarcely listened to, but specific environmental coverage in general was largely avoided. This relative lack of interest in media coverage of environmental issues should not be taken, however, to indicate a lack of engagement with environmental issues. Participants expressed a great deal of concern about their local environment with urban participants focusing on problems of air pollution, while rural participants emphasised the impact of water shortages and chemical contamination of farmland:

“Air pollution is growing. Today, you definitely have to cover your nose while you are closer to Bagmati (river).” (Milan/ITP)

"While there used to be five households dependent on the drinking water in this hill (shows the area), there are fifteen households now for the same amount of water. Maybe that is why there is a scarcity of water here.” (Kamala, CFUG-1) 
“The quality of soil is degraded to that extent that even the chemicals do not work now. It does affect environment a lot.” (Kamala/CFUG-1)

These problems were experienced as having direct impacts on participants' lives. The underlying cause of these problems was seen to be ineffective state intervention to manage the impacts of a growing population and curb industrial encroachment. Thus, in direct contrast with Batabaran Dabali's focus on climate change and its international causes, we saw ordinary people concerned about problems which they could see directly affecting their local environment for which they blamed the Nepalese government and national industry. Discussion in the focus groups revolved around local environmental problems with climate change receiving scant attention. All participants, however, including those from rural villages, were familiar with the terms 'global warming' and 'climate change' and had some knowledge about the issue. When climate change was mentioned it was often in the context of startling facts which they had assimilated from media reports:

"We heard a lot from the media that there is no snow in the Himalayas due to the rise in temperature. This could bring a big challenge to Nepal.” (Gaurav/CFUG-1)

"I have heard (from the media) that the temperature of the earth is increasing due to climate change. I have also heard that the height of Mt. Everest has decreased ... something like from $8848 \mathrm{~m}$ to $8846 \mathrm{~m}$. This is distressing.” (Gyaan/LF)

Subsequent research in Nepal by Colom and Pradhan (2013) reinforces this observation, with their respondents also recounting coverage of climate change and expressing views about potential catastrophic impacts for Nepal. Such media coverage of climate change was not, however, accepted uncritically. In our study for the rural groups a recurrent complaint was 
that there was too much coverage of climate change and that despite such extensive coverage there was little information about practical responses that might be adopted:

“After the conference (Copenhagen conference 2009), there was no clear message on any action plan for balancing nature and the role of Nepal on climate change. None of the media were seen to be focusing on it. Even the television and radio never had messages on what we should be doing to mitigate climate change.” $($ Gyaan/LF)

“Yeah, we agree. No such messages from the media. We don’t know how to curb the problems brought by climate change.” (Lila/LF)

Here, we see rural participants looking for media coverage which would give them some sense of how they could respond locally as “active citizens” (Gregory \& Miller, 2000, p97). This sense of their desire to take practical local action to mitigate impacts resonated with accounts they provided of community mobilisation in small scale environmental conservation (see also Colom and Pradhan, 2013). For example, participants from a rural group recounted how the villagers had applied their experiential knowledge once they realised that their activities had been damaging the environment:

"We came to know about the nature of the soil on our own. We found that the paper and plastic we dumped years ago didn't degrade. Then we realised that it is harmful to our soil.” (Kulchandra/LF)

Not only did rural participants find that media coverage of climate change rarely provided them with useful information they were also critical of the complexity of the information: 
"It (the environmental story such as climate change) is not easy to understand. They are not like agricultural programmes in Radio Nepal.” (Lila/LF)

“They (the media) talk about all the big things (e.g. issues related to climate change). Some we understand but we don't understand many terms. We are not educated, so how can we understand what big people say.” (Archana/CFUG-2)

By referring to the people in the media as "big people”, a clear contrast between the poor and less literate rural people and the rich and educated city people is apparent. A framing of the discussions in the media as "big things" suggests that the participants exclude themselves from the expert media discussion. Media discourse is constructed as "big people" talking about "big things” which are incomprehensible to 'little people' with 'little' local concerns. As Colom and Pradhan note, the Nepalese media have "talked about the topic at a macro or scientific level, which people have found difficult to relate to” (2013, p35). For rural participants, environmental understanding was rooted in everyday interaction with their surroundings (Wynne, 1996; Irwin \& Michael, 2003):

\footnotetext{
"What we see in front of our eyes all comes into the environment, the things which are around our house.” (Binita, CFUG-2)
}

"In my opinion the environment is what we are seeing in front of us now." (Gyaan/LF)

“Air, water, our surrounding is the environment.” (Kamala/CFUG-1)

The environment of concern for participants was that which they experienced and had direct sensory engagement with. While climate change impacts could be constructed as direct 
localised impacts affecting the lives of Nepalese people (and indeed sometimes were on Batabaran Dabali) such local accounts of climate change impacts did not emerge in the focus groups and the media construction of climate change was viewed by participants as concerned with expert analyses of problems distanced from their everyday lives.

\section{Discussion}

Content analysis of Batabaran Dabali showed that climate change is the key facet through which Batabaran Dabali frames the environment and that coverage relies heavily on expert sources. Although the constructions of climate change on this programme share some similarities with those of media in developed nations in terms of the use of alarmist and disaster discourses, the differences are more striking. In Nepal, as in India (Billett, 2009) climate change is constructed as certain and an already evident problem as well as a future risk. While impacts at a national level are emphasised, responsibility for the problem is laid firmly at the feet of the developed nations. In Batabaran Dabali, expert interviewees framed Nepal as a victim of climate change as well as of developed nations. A portrayal of Nepal as a victim reflects the construction of a growing polarity between developed and developing nations. Pittock points out that "[a]ny successful international effort to limit climate change and to cope with its impacts requires that both developed and developing countries play a significant role” (2009, p. 254) Thus, it seems important that Batabaran Dabali enables more interactive discussions on climate change that highlight the role of both worlds in combating the problem.

While climate change and its international causes dominated Batabaran Dabali's coverage, in the focus groups, discussion of local problems with national causes predominated. While participants were aware of the impact of climate change and identified the media's role as 
significant in establishing it as a pressing issue, the dangers were typically constructed as distant and remote. What Nepalese participants had learnt about climate change from the media seemed to be a series of alarming facts rather than any useful information about ways in which local impacts or risks could be mitigated. Coverage of climate change was depicted as overdone, complex and overly focused on the activities of elites with little relevance to the lives of ordinary people.

In order to improve climate change communication through the Nepalese media, particularly Batabaran Dabali, a “cultural model” of "risk communication” (Plough \& Krimsky, 1987) involving collaboration between citizens, experts and agencies should be considered. A fundamental shift is needed from communicating climate change to Nepali people to communicating it with them - a move away from attempts to fill deficits of knowledge with information in favour of a more participatory communicatory process (Wibeck, 2012). This might include the development of more interactive programmes with the involvement of rural people and mechanisms for the development and distribution of localised programmes in local media.

Radio Sagarmatha explicitly aims to engage with communities and promote the rights of ordinary Nepalese people. Our focus group participants seldom listened to the station, however, and indicated that in general environmental programmes were of little interest to them. Somewhat surprisingly we found that our participants used television more than radio, and when they talked about media coverage they often referred to what they saw on television. Those most likely to listen to Batabaran Dabali were urban professionals - hardly 'the voiceless' the programme claims to represent and communicate with. While this small scale qualitative research does not provide a representative measure of the programme's 
audience size or response it does provide some important suggestions. If media channels are to stimulate engagement with climate change it may not work best through explicitly environmental stations or programmes. Rather, story lines in popular programmes and incorporation of discussion of the issues into mainstream programming may be a more effective way of "emotionally anchoring” (Hoijer, 2010) and integrating climate change into everyday conversations (Olausson, 2011). In common with most existing work we focused on analysing explicitly environmental content in the media, choosing an environmental programme as our data. A challenge for future research may be to cast the net wider and to explore when and how climate change ever surfaces in mainstream programming.

The analysis of Batabaran Dabali found complex and competing constructions of climate change in expert discourses, while simple information on coping with, or preparing for, the impacts of climate change was ignored. A potentially important role for the media - in both developed and developing countries - is to facilitate practical discourses on coping with climate change. This will not require expert debate about the technical, political and economic dimensions of climate change so much as coverage which engages with ordinary people and concrete local problems.

\section{Acknowledgements}

We would like to thank anonymous reviewers as well as Guest Editors Ulrika Olausson and Peter Berglez for insightful comments and feedback on previous versions of this article. We would also like to thank ORSAS (Overseas Research Students Award Scheme) and URS (University Research Scholarship) of the University of Surrey for funding the research. 
Notes

i We recognise that the terminology of developing/developed world is problematic as it implicitly assumes that parts of the world (usually Europe and the USA) can be labelled un-problematically as 'developed' and that other countries are moving along a single path towards such 'development'. No alternative terminology is without problems, however, and so we use the terms developed/developing here as a shorthand with recognition of their limitations.

ii Batabaran Dabali, literally meaning environmental discussion forum, is a half-hour weekly discussion programme aired on Radio Sagarmatha. The programme includes interviews, environmental news coverage and field reporting.

iii Other codes were Biodiversity Conservation, Interim Constitution, Environmental Impact, Landscape Conservation, Environment and Citizen Rights, Environmental Media Coverage, Others' (which included nature, natural resources, tourism, ministry-related issues)

iv In total 8 groups were conducted, 6 with lay people and 2 with 'experts' representing various Nepalese environmental organisations. As we focus here on lay constructions of climate change we have excluded these expert environmental groups from analysis. The development professionals group were included as they belonged to humanitarian organisations and did not have particular environmental expertise.

v Questions included: What is 'environment' to you? What comes into your mind when you refer to the environment? Do you think there are problems in the environment? Which environmental problems do you think are most serious in Nepal? How do you know about environmental issues? Which media do you access the most? What do you think about the environmental media in Nepal?

vi The city professionals were educated to degree level, many had higher qualifications from international universities. However, many rural participants could hardly write their names, some had primary education but very few had secondary level education. 
vii To preserve anonymity pseudonyms have been used for focus group participants. The names of the interviewees/interviewers in Batabaran Dabali have not been altered since the aired programme is publicly available.

viii The headline is the topic as set out by the presenter/interviewer.

ix Churia area "is the range gradually elevated from Terai plains up to 1,800 $\mathrm{mt}$ from the sea level, stretched almost the entire length of the country from east to west" (CSRC, 2005, p16).

x Lumbini is a Buddhist pilgrimage site in the Rupandehi district of Nepal.

xi Participants were able to choose from TV, radio, newspaper and the Internet and asked to grade the options from 1 (most used) to 4 (least used). Some participants marked more than one option as most used and few gave a grade to each option.

xii Codes used for the groups are: Development Professionals (DP), IT professionals (ITP), Business Professionals (BP), one rural group of farmers in Sindhupalchowk district (LF), Community Forest User Groups in Kavrepalanchowk district as CFUG-1 and CFUG-2. 


\section{References}

Anderson, A. (1997). Media, culture and the environment. London: UCL Press.

Antilla, L. (2005). Climate of scepticism: US newspaper coverage of the science of climate change. Global Environmental Change, 15, 338-352.

doi:10.1016/j.gloenvcha.2005.08.003

Bell, A. (1991). The language of news media. Oxford, UK and Cambridge, MA: Blackwell.

Billett, S. (2009). Dividing climate change: Global warming in the Indian mass media. Climatic Change, 99 (1-2), 1-16.

Birbili, M. (2000). Translating from one language to another. Social research update, 31. Retrieved from http://sru.soc.surrey.ac.uk/SRU31.html

Burningham, K. (1998). A noisy road or noisy residents?: A demonstration of the utility of social constructionism for analysing environmental problems. The Sociological Review, 46(3), 536-563. doi:10.1111/1467-954X.00130

Carvalho, A. (2007). Ideological cultures and media discourses on scientific knowledge: Rereading news on climate change. Public Understanding of Science, 16, 223-243.

Central Bureau of Statistics Nepal. (2012). National population and housing census 2011 (national report). Kathmandu: Central Bureau of Statistics.

Climate Change Vulnerability Index. (2011). Big economies of the future - Bangladesh, India, Philippines, Vietnam and Pakistan - most at risk from climate change. United Kingdom: Maplecroft. Retrieved July 2, 2013, from http://maplecroft.com/about/news/ccvi.html.

Coffey, A. \& Atkinson, P. (1996). Making sense of qualitative data: Complementary research strategies. Thousand Oaks, CA: Sage.

Colom, A. \& Pradhan, S. (2013). How the people of Nepal live with climate change and what communication can do. London: BBC Media Action.

Corbett, J. B., \& Durfee, J. L. (2004). Testing public (un)certainty of science: Media representations of global warming. Science Communication, 26(2), 129-151. doi:10.1177/1075547004270234 
CSRC (Community Self Reliance Centre). (2005). Churia conservation, livelihood and land rights: Unravelling the complexities. Kathmandu: CSRC, Supported by CARE Nepal.

Dirikx, A., \& Gelders, D. (2010). Ideologies overruled? An explorative study of the link between ideology and climate change reporting in Dutch and French newspapers. Environmental Communication, 4, 190-205.

Dispensa, J. M., \& Brulle, R. J. (2003). Media’s social construction of environmental issues: Focus on global warming - A comparative study. International Journal of Sociology and Social Policy, 23(10), 74-105. doi: 10.1108/01443330310790327

Doulton, H., \& Brown, K. (2009). Ten years to prevent catastrophe? Discourses of climate change and international development in the UK press. Global Environmental Change, 19, 191-202. doi:10.1016/j.gloenvcha.2008.10.004

Equal Access. (2006-2007). The broadcast audience survey: Media, ownership and accessibility. Kathmandu: Equal Access. Retrieved 20 August 2009, from http://www.nepalradio.org/p2_broadcasting.htm

Ereaut, G., \& Segnit, N. (2006). Warm words: How are we telling the climate story and can we tell it better? London: Institute for Public Policy Research.

Gregory, J., \& Miller, S. (2000). Science in public: Communication, culture and credibility. Cambridge, MA: Basic Books.

Hannigan, J. (2006). Environmental sociology (2nd ed.). London: Routledge

Hansen, A. (1991). The media and social construction of the environment. Media, Culture \& Society, 13, 443-458. doi:10.1177/016344391013004002

Hansen, A. (2010). Environment, media and communication. London and New York: Routledge.

Hansen, A., Cottle, S., Negrine, R., \& Newbold, C. (1998). Mass communication research methods. Hampshire, NY: Palgrave.

Himalayan Climate Initiatives. (2013). The founding declaration. Kathmandu: Himalayan Climate Initiative. Retrieved 27 February, 2013, from http://himalayanclimate.org/hci/the-initiative/

Hoijer, B. (2010). Emotional anchoring and objectification in the media reporting on climate change. Public Understanding of Science, 19, 717-731. doi:10.1177/0963662509348863 
Hulme, M. (2007). Mediated messages about climate change: Reporting the IPCC fourth assessment in the UK print media. A Submission to Science Communication, 124. Retrieved from http://mikehulme.org/wp-content/uploads/2007/09/hulme-allmediated-messages.pdf.

ICIMOD. (2010). Climate change vulnerability of mountain ecosystems in the Eastern Himalayas. Kathmandu: ICIMOD.

Irwin, A., and Michael, M. (2003). Science, social theory and public knowledge. Maidenhead: Open University Press.

Kenix, L. J. (2008). Framing science: Climate change in the mainstream and alternative news of New Zealand. Political Science, 60(1), 117-132. doi:10.1177/003231870806000110

Khatiwoda, S. (2011). Vulnerability assessment of indigenous people's livelihood due to climate change in Darakh VDC of Kailali district. Kathmandu: SchEMS, Pokhara University.

Lester, L. (2010). Media and environment: Conflict, politics and the news. Cambridge: Polity.

Mason, J. (2002). Qualitative researching (2nd ed.). London: Sage.

Nepal Television. (2012). About Us. Kathmandu: Nepal Television. Retrieved 26 February, 2012, from http://ntv.org.np/index.php?option=com_content\&view=article\&id=9\&Itemid=2

Nisbet, M., \& Mooney, C. (2007). Science and society: Framing science. Science, 316(5821), 56. doi:10.1126/science.1142030

Olausson, U. (2011) “We're the ones to blame”: Citizens' representations of climate change and the role of the media. Environmental Communication, 5, 281-299.

Oxfam International (2008). Climate, poverty and justice; What the Poznan UN Climate Conference needs to deliver for a fit and effective global climate regime Briefing Paper 124. Retrieved from http://www.oxfam.org/en/policy/climatepoverty-and-justice

Peters, H. P., \& Heinrichs, H. (2008). Legitimizing climate policy: The "risk construct" of global climate change in the German mass media. International Journal of Sustainability Communication, 3, 14-36

Pittock, A. B. (2009). Climate change: The science, impacts and solution (2nd ed.) Collingwood, VIC: CSIRO. 
Plough, A., \& Krimsky, S. (1987). The emergence of risk communication studies: Social and political context. Science, Technology, Human Values, 12, 4-10.

Pomerantz, A. (1986). Extreme case formulations: A way of legitimizing claims. Human Studies, 9, 219-229. doi:10.1007/BF00148128

Potter, J., \& Wetherell, M. (1987). Discourse and social psychology: Beyond attitudes and behaviour. London: Sage.

Pringle, I. (2008). Pioneering community radio: Impacts of IPDC assistance in Nepal. France: UNESCO IPDC.

Radio Sagarmatha brochure. (n.d.). Background. Kathmandu: Radio Sagarmatha. Retrieved 5 December 2009, from http://www.radiosagarmatha.org/en/about-us

Sampei, Y., \& Aoyagi-Usui, M. (2009). Mass-media coverage, its influence on public awareness of climate-change issues, and implications for Japan's national campaign to reduce greenhouse gas emissions. Global Environmental Change, 19, 203-212. doi:10.1016/j.gloenvcha.2008.10.005

Seale, C. (2004). Coding and analysing data. In C. Seale (Ed.), Researching society and culture (2nd ed., pp. 305-321). London: Sage.

Sharples, D.M., (2010) Communicating climate science: Evaluating the UK public's attitude to climate change. Earth and Environment, 5, 185-205

Shrestha, S. (2012). Constructions of the environment in Nepal: Environmental discourses on air and on the ground. Unpublished PhD Thesis. University of Surrey, Guildford.

Spicer, N. (2004). Combining qualitative and quantitative methods. In C. Seale (Ed.), Researching society and culture (2nd ed., pp. 293-304). London: Sage.

Takahashi, B. (2011). Framing and sources: A study of mass media coverage of climate change in Peru during the V ALCUE. Public Understanding of Science, 20, 543557. doi:10.1177/0963662509356502

Tonkiss, F. (2004). Using focus groups. In C. Seale (Ed.), Researching society and culture (2nd ed., pp. 193-206). London: Sage.

van Dijk, T. A. (1998). Opinions and ideologies in the press. In A. Bell and P. Garrett (Eds.), Approaches to media discourses (pp. 21-63). Oxford, MA: Blackwell.

Weingart, P., Engels, A., \& Pansegrau, P. (2000). Risks of communication: Discourses on climate change in science, politics, and the mass media. Public Understanding of Science, 9, 261-283. doi: 10.1088/0963-6625/9/3/304 
Whitmarsh, L. E. (2005). A study of public understanding of climate change in the South of England. Bath: University of Bath.

Wibeck, V. (2012). Social representations of climate change in Swedish lay focus groups: Local or distant, gradual or catastrophic? Public Understanding of Science, 0(0), 1-16.

Wynne, B. (1996). May the sheep safely graze? A reflexive view of the expert-lay knowledge divide. In L. S. B. Szerynskyi \& B. Wynne (Eds.), Risk, environment and modernity: Towards a new ecology (pp. 44-83). London: Sage.

Yearley, S. (1991). The green case: A sociology of environmental issues, arguments, and politics. London: Harper Collins. 